\title{
Knowledge Sharing Behaviour and Intensive Care Nurse Innovation \\ The Moderating Role of Control of Care Quality
}

Li-Ying, Jason; Paunova, Minna ; Egerod, Ingrid

\author{
Document Version \\ Accepted author manuscript \\ Published in: \\ Journal of Nursing Management
}

DOI:

10.1111/jonm. 12404

Publication date:

2016

License

Unspecified

Citation for published version (APA):

Li-Ying, J., Paunova, M., \& Egerod, I. (2016). Knowledge Sharing Behaviour and Intensive Care Nurse Innovation: The Moderating Role of Control of Care Quality. Journal of Nursing Management, 24(7), 943-953. https://doi.org/10.1111/jonm.12404

Link to publication in CBS Research Portal

\section{General rights}

Copyright and moral rights for the publications made accessible in the public portal are retained by the authors and/or other copyright owners and it is a condition of accessing publications that users recognise and abide by the legal requirements associated with these rights.

\section{Take down policy}

If you believe that this document breaches copyright please contact us (research.lib@cbs.dk) providing details, and we will remove access to the work immediately and investigate your claim. 


\section{Knowledge Sharing Behaviour and Intensive Care Nurse Innovation: The Moderating Role of Control of Care Quality Jason Li-Ying, Minna Paunova, and Ingrid Egerod}

Journal article (Accepted version)

This is the peer reviewed version of the following article: Knowledge Sharing Behaviour and Intensive Care Nurse Innovation : The Moderating Role of Control of Care Quality. / Li-Ying, Jason; Paunova, Minna ; Egerod, Ingrid. In: Journal of Nursing Management, Vol. 24, No. 7, 2016, p. 943-953, which has been published in final form at http://dx.doi.org/10.1111/jonm.12404.

This article may be used for non-commercial purposes in accordance with Wiley Terms and Conditions for Self-Archiving.

Uploaded to Research@CBS: July 2017 
NOTE: This is an unedited, uncorrected copy of an article forthcoming in Journal of Nursing Management. Full bibliographic details of the early-view online version:

Li-Ying, J., Paunova, M., \& Egerod, I. (2016). Knowledge sharing behaviour and intensive care nurse innovation: the moderating role of control of care quality. Journal of Nursing

Management. DOI: $10.1111 /$ jonm.12404

Knowledge sharing behaviour and intensive care nurse innovation:

The moderating role of control of care quality

\author{
Jason Li-Ying, PhD \\ Department of DTU Management Engineering \\ Technical University of Denmark \\ 2800 Kgs. Lyngby, Denmark \\ yinli@dtu.dk \\ Minna Paunova, $\mathrm{PhD}$ \\ Department of International Business Communication \\ Copenhagen Business School \\ 2000 Frederiksberg, Denmark \\ mp.ibc@cbs.dk \\ Ingrid Egerod, RN, MSN, PhD \\ Rigshospitalet, Trauma Center \\ Health \& Medical Sciences \\ University of Copenhagen \\ ingrid.egerod@regionh.dk
}

\title{
Source of funding
}

This research was supported by the Danish Council for Strategic Research (DSF), grant number 0603-00297B. 


\title{
Knowledge sharing behaviour and intensive care nurse innovation: The moderating role of control of care quality
}

\begin{abstract}
Aims:

This study investigates the influence of intensive care unit nurses' knowledge sharing behaviour on nurse innovation, given different conditions of care quality control.

\section{Background:}

Health-care organisations face an increasing pressure to innovate while controlling care quality. We have little insight on how the control of care quality interacts with the knowledge sharing behaviour of intensive care nurses to affect their innovative behaviours.

\section{Methods:}

We developed a multi-source survey study of more than 200 intensive care nurses at 22 intensive care units of 17 Danish hospitals. Two versions of the questionnaire were used - one designed for nurse employees and the other for the managing nurse(s). An ordinary least squares regression analysis was used to test the hypotheses.

\section{Results:}

Different aspects of knowledge sharing affect innovation differently, depending on the strength of the control of care quality within the unit.

\section{Conclusions:}

The increasing pressures to implement the control of care quality and innovate may be conflicting, unless handled properly.

\section{Implications for nursing management:}

Process control at intensive care units should be loosened, when personal interaction between intensive care nurses is encouraged to stimulate nurse innovations. Alternatively, managers may develop a climate where helping others, especially with younger colleagues, offsets the negative effects of strong process control.
\end{abstract}

Keywords: innovation, knowledge sharing, quality of care, nursing, intensive care 


\section{Knowledge sharing, control of care quality, and innovation in intensive care nursing}

\section{INTRODUCTION}

In the early 1990s, health care organizations recognized that they were facing a critical choice between innovating and being replaced by organizations that do; a tough choice (Manion, 1993). Nowadays, health care organizations have witnessed an increasing number of evidence-based innovations, often through the creative potential of health care professionals. In the health care system, nurses provide up to $80 \%$ of primary care and are thus well positioned to contribute to innovation in practice (Hughes, 2006). Therefore, how to encourage innovation behaviors among nurses has been of interest to both healthcare practitioners and scholars; yet, there is a need for more research in nursing innovation (ICN, 2009; Tross \& Cavanagh, 1996).

In the past, a commonly accepted view was that most of the innovations affecting nursing were initiated outside nursing. Nurses were simply regarded as adopters of innovation and critical for the diffusion of health care innovation. However, recent developments in health care management have recognized that frontline clinicians, who are the key to safety and quality of care, are not only adopters of innovation, but also origins of change in clinical practice, thus themselves an important source of innovation in health care (McSheery \& Douglas, 2011). Within the context of nurse innovation, there has been a solid body of research on nurses' challenges to embrace change (Stevens, 2001), the impact of transformational leadership (Weng et al., 2015), organizational and social climate (Richer et al., 2009), and training (Syme \& Stiles, 2012).

While these contextual factors are important for nurse innovation, innovation will not take place unless knowledge gained by motivated and competent nurses is shared among them. The literature on knowledge management has a long tradition in suggesting that work 
groups engaged in active knowledge sharing demonstrate enhanced individual and group performance (Cummings, 2004). More specifically, scholars have found that knowledge sharing behaviors among group members positively contribute to the group's innovation capability (Lin, 2007; Sáenz et al., 2009). To date, we have little knowledge about how different modes of nurses' knowledge sharing behavior are related to nurse innovation within intensive care units (ICUs).

Meanwhile, another critical role that practical clinicians, such as ICU nurses, play is contributing to the quality of care (Pronovost et al., 2001; Nelson et al., 2006). Therefore, health care organizations put a premium on developing, implementing and evaluating measures for quality of care (Pronovost et al., 2001; Rademakers et al., 2011). These measures are used as a control mechanism in nursing management to ensure the quality of care provided to patients. Although some insights on which types of care quality measures are more effective than others with regard to patients' overall assessment of healthcare quality are available (Rademakers et al., 2011), we have little insights on the possible influence of quality control on nurse innovation, particularly as it interplays with knowledge sharing behavior. Thus, we pose the following question: would the control of care quality at ICUs make a difference for innovation when ICU nurses share their knowledge? Here, control of care quality is a construct at the group (intensive care unit) level, while knowledge sharing and innovation are conceptualized at the individual level.

Following this line of inquiry, this study develops a number of hypotheses, based on the literature in knowledge management, innovation, and quality of care. The empirical base used to test these hypotheses is a survey conducted with the "Forskernetværk for Intensivsygepleje" (Research network for intensive care nurses), reaching out to the population of ICU nurses in Denmark. By revealing the interactive relationships among knowledge sharing behavior, control of care quality and innovation performance of ICU 
nurses, we aim at providing implications for health care management with regard to how to foster nurse innovation by promoting knowledge sharing and adjusting control of care quality.

\section{THEORY AND HYPOTHESES}

\section{Knowledge Sharing and Innovation}

Innovation consists of an ongoing pursuit of harnessing new and unique knowledge, which is created through a continuous process where boundaries and constraints stemming from limited individual cognition are extended and overcome by acquiring a new context, a new view of the world, and new knowledge (Subramaniam \& Youndt, 2005). By interacting and sharing knowledge with others, an individual may enhance his or her capacity to define a situation or problem, and apply his or her knowledge so as to act and solve the problem (Nonaka et al., 2006). Knowledge sharing can be defined as a social interaction culture, involving the exchange of employee knowledge, experiences, and skills through the whole department or organization (Lin, 2007), as well as the provision or receipt of task information, know-how, and feedback regarding a practice or procedure (Hansen, 1999; Cummings, 2004). Knowledge sharing creates opportunities to maximize organizational capability to reach its goals and positively contribute to the effectiveness and efficiency of an organization, leading to enhanced competitiveness (Reid, 2003).

The extant literature in knowledge management has shown that different means and processes of knowledge sharing within various types of organizations have positive impacts on individual and organizational innovation capabilities (Lin, 2007; Sáenz et al., 2009; Wang \& Wang, 2012). Therefore, it is commonly recognized in the literature on knowledge management and innovation that knowledge sharing is essential for creating new knowledge and thus for innovating (Dalkir, 2005). 
The knowledge shared in work groups can be tacit, codified, or embodied in routines (Cummings, 2004; Wang \& Wang, 2012). Knowledge sharing comprises a set of shared understandings related to providing employees access to relevant information and building and using knowledge networks within organizations (Hogel et al., 2003). Knowledge sharing in ICU nurse groups might entail developing coaching and guidelines, development of and contributing to research committees, seminars, journal clubs, and newsletters to update research skills. ICU nurses may also share knowledge in informal ways such as chatting in the coffee room and canteen, sharing experiences that may benefit the group during ICU nurse meetings, and/or communicating online outside of working hours. By engaging in these knowledge sharing activities, it is expected that ICU nurses become more innovative in general. Based on the ideas derived from the nursing practice and shared within the unit, more evidence-based innovations can be initiated and developed with the help of other clinicians and the support of leadership and management (Åmo, 2006). In sum, the above discussion suggests the following hypothesis:

Hypothesis 1: Knowledge sharing among ICU nurses is positively associated with individual innovation.

\section{Control of Care Quality in Relation to Innovation}

Quality of health care has become a national and international policy issue (Pronovost et al., 2001; Nelson et al., 2006). The Institute of Medicine (IOM) defines health care quality as "the degree to which health services for individuals and populations increase the likelihood of desired health outcomes and are consistent with current professional knowledge." Practice patterns and the quality of medical care vary widely. Health care providers are therefore increasingly interested in having objective measures of quality and information about their performance, as patients and purchasers are beginning to make health care purchasing decisions based on quality of care. 
In particular, ICU nurses play a key role in patients' recovery, as they must respond continuously and quickly to the needs of patients and families, carry out procedures accurately, and interact with the most intense emotional aspects of life. They work in demanding and stressful work environments to help patients in critical conditions. Among others, quality of care has become a major issue in ICUs (Donchin et al., 1995). ICU nurses face various types of performance obstacles in performing patient care tasks, threatening the quality and safety of care provided (Gurses \& Carayon, 2007). As consumers, payers, and regulatory agencies require evidence regarding quality of care, the demand for ICU quality measures will likely grow. As a result, researchers have made great efforts in specifying and developing ICU quality indicators (Berenholtz et al., 2002), whereas health management practitioners pay a great attention to implementing controls over the measures of care quality in ICUs (Pronovost et al., 2001; Rademakers et al., 2011). This is the case even though concepts such as empowerment, governance, leadership and participative decision-making have long replaced the traditional authoritarian style of management (Prince, 1997).

Pronovost and colleagues (2001) suggested that measures of care quality in ICUs can be categorized into structure, process and outcome measures (Donabedian, 1996). In many instruments designed to measure patients' experiences with quality of healthcare, such as the American Consumer Assessment of Health Plans and Providers (CAHPS) and the Dutch Consumer Quality-index (CQ-index), elements of all three components are indeed used. Other researchers further developed and tested the care quality measures following Pronovost et al.'s (2001) measurement design and found differentiated effectiveness across different types of measures of quality of care (Nelson et al., 2006; Rademakers et al., 2011).

While a comprehensive and well-implemented measurement system of quality of care at ICUs is important to ensure and improve quality of care, a strong control by excessive use of measures of care quality may have a number of disadvantages. First, just as any other 
organizations, health care institutions need to balance between exploitation through operational excellence (efficiency) and exploration through innovation (March, 1991). High levels of control over performance measures tend to make ICU nurses' practice highly oriented towards operational excellence (efficiency) instead of creating new paths (Spear, 2005). Thus, the positive effects created by knowledge sharing on innovation might be compromised in a way that shared knowledge is mostly put into use to make incremental improvements of existing processes and methods instead of initiating boundary-breaking initiatives and trying out new approaches in care provision.

Second, clinicians' innovation generally needs leadership support and encouragement (Syme \& Stiles, 2012; Weng et al., 2015). Thus, excessive use of measures of care quality at ICUs may impose demanding management burden onto ward nurses, research nurses and manager nurses, who will be overwhelmed to keep track of quality of care at his or her ICU. The consequence is that these leading nurses will have little time and motivation to facilitate knowledge sharing and stimulate innovative ideas within the ICU. Recent studies support this argument. For instance, workload redistribution can support increased quality of care by enabling ward managers to spend less time on administrative tasks thus having more time to spend with patients and leading staff, focusing on the issue of innovation and increasing effectiveness (Locke et al., 2011). In the same vein, a positive effect of shared governance between nurse managers and staff nurses has also been found (Ott \& Ross, 2014), indicating that time and effort are very much needed for nurse managers to deal with issues other than controlling care quality. Based on these arguments, we hypothesize the following:

Hypothesis 2: Control of care quality moderates the positive relationship between knowledge sharing among ICU nurses and individual innovation so that the stronger the control of care quality, the weaker this relationship. 


\section{METHODS}

\section{Instrument and Pilot Study}

After conducting interviews about knowledge sharing and innovation with a small sample of nurses, we conducted a multi-source survey study. We developed two versions of a survey questionnaire - one aimed at nurse employees, working with patients (employee version) and one designed for the managing nurse(s) employed in the unit (manager version). The employee version of the questionnaire was designed to tap into innovation, knowledge sharing behaviors and control variables (e.g., individual demographics). The manager version captured control of quality of care, as well as questions about hospital and ICU size (e.g., number of beds). The study constructs were all measured with validated psychometric instruments on five-point Likert scales (see Appendix for a list of survey items used). All instruments were originally designed in English and were translated into Danish and backtranslated by two independent professional translators. Inconsistencies were resolved by one of the authors, who is an English and Danish bilingual, and who works within intensive care nursing in Denmark.

We conducted a pilot study in one large hospital with four intensive care units. The final sample of the pilot study included 11 manager and 62 employee responses. In addition to the main variables of the study, the pilot version of the questionnaire included open questions, where respondents shared any comments they had on the survey instrument. Furthermore, following data collection, interviews were conducted over the phone and faceto-face in a small focus group with a number of respondents, who gave suggestions and comments on improving the questionnaire. The psychometric properties of the instrument were evaluated. In addition, the length of the survey was reduced in order to ease the cognitive load on participants, and unclear questions were clarified and further adapted to the local context. 


\section{Ethical Approval}

Ethical approval was obtained from the "Forskernetværk for Intensivsygepleje" (Research network for intensive care nurses in Denmark). Careful consideration was taken to ensure the confidentiality of individual participants' responses. Respondents provided consent prior to answering the questionnaire.

\section{Sample}

In June 2014, we distributed the final questionnaire through the professional network of Danish intensive care researchers, fsaio.net. The questionnaire was sent to 45 researchers, who were members of fsaio.net and who were employed in 39 intensive care units at 29 different hospitals across Denmark. The hospital that participated in the pilot study was excluded. Researchers received the two versions of the questionnaire and were asked to distribute the questionnaires further within their units, specifically to at least one manager/head nurse (the manager version) as well as to all regular nurses (employee version), so that 254 nurses completed the employee version and 67 nurses completed the manager version. Because of the requirements of this matched sample, usable data at both employee and manager level were collected from 22 units in 17 hospitals, for a final usable sample of 180 nurses (at the employee level). $94.5 \%$ of these nurses were female, and the mean age was 44. On average, respondents had almost 17 years of nursing experience and $80 \%$ had completed a two year intensive care nursing certification.

We are aware that a Web-based survey design holds a number of possible biases. We tested for the most important possible bias, namely response bias, a potential problem that some nurses (e.g., due to their general interest and motivation) may find it more interesting to participate in the survey than others (Armstrong \& Overton, 1977). In our case, this implies that innovative nurses and those who share knowledge more than others were more likely to answer the questionnaire faster. To test for this potential bias, following Jeppesen and 
Frederiksen (2006), we compared the earliest $10 \%$ of respondents with the last $10 \%$ of respondents and tested for differences in the self-reported measures of (a) innovation (diff. = $0.04, \mathrm{t}(34)=0.23, \mathrm{p}>0.10)$ and $(\mathrm{b})$ knowledge sharing $($ diff. $=-0.02, \mathrm{t}(34)=-0.17, \mathrm{p}>0.10)$. There were no significant differences between these two groups; thus, no bias was discovered.

\section{Measures}

Innovation. In the employee version of the questionnaire, we used the four general innovation performance items developed by Welbourne, Johnson, and Erez (1998) to capture nurse innovation. This scale reflects not only the development of novel and useful ideas but also the implementation and application of these ideas. Respondents (of the employee version of the questionnaire) rated their innovation performance ("When I'm at work, I'm good at...") on a five-point Likert scale ( $1=$ strongly disagree to $5=$ strongly agree). Items included "Coming up with new ideas", "Working to implement new ideas", "Finding improved ways to do things" and "Creating better processes and routines" $(\alpha=0.88)$.

Knowledge sharing. We adapted a measure of knowledge sharing behaviors developed by Yi (2009). This measure was included in the employee version of the questionnaire and includes 18 items divided into three subscales $(\alpha=0.86)$ : knowledge sharing through written contributions, knowledge sharing through organizational communication, and knowledge sharing through personal interaction. Respondents were asked to indicate how often they engage in a certain behavior ("How often do you..."; $1=$ never, $2=$ rarely, $3=$ sometimes, $4=$ often, $5=$ all the time). Knowledge sharing through written contributions was measured with six items such as "Participate in writing local clinical guidelines" and "Inform colleagues in writing about the projects you participate in" $(\alpha=0.76)$. Knowledge sharing through organizational communication was measured with six items such as "Answer questions of others in department meetings" and "Tell success stories of nursing experiences in department meetings" $(\alpha=0.86)$. Finally, knowledge sharing 
through personal interaction was measured with six items such as "Support less experienced colleagues outside your normal working hours" and "Spend time on personal conversations with other critical care nurses to help them with work-related problems (e.g., conversations over lunch, over the phone)" $(\alpha=0.69)$.

Control of care quality. Measures of control of care quality were adapted from Pronovost et al. (2001) and were included in the manager version of the questionnaire. Control of care quality includes fifteen items in three subscales $(\alpha=0.86)$ : structure, process and outcome control. Structure measures refer to how care is organized; process measures refer to what care providers do; outcome measures capture what happens to patients. Respondents were asked to indicate the extent to which they agree $(1=$ strongly disagree to 5 $=$ strongly agree) that their hospitals and intensive care units make high demands regarding a set of issues such as "presence of intensive care physicians" and "daily rounds of intensive care physicians" (structural control of care quality), "daily interruption of sedation" and "prevention of failed extubation" (process control of care quality) and "optimizing the family and patient satisfaction with care" and "optimizing pain management" (outcome control of care quality). In approximately half of the units surveyed, only one manager filled out the questionnaire to indicate her/his perception of control. Nonetheless, ICC was calculated to estimate within-unit similarity in managers' perceptions of control, in the case that more than one manager filled out the questionnaire. Intraclass correlations of individual ratings (ICC(1) $=0.17)$ and the reliability of mean ratings $(\operatorname{ICC}(K)=0.31)$ were adequate, particularly given the very small number of respondents within each unit (cf. LeBreton \& Senter, 2008).

Controls. We controlled for sex, age, and nursing experience (in years). In addition, we controlled for having completed official intensive care nursing training $(0=$ no, $1=$ yes $)$, and the number of working hours per week. All of these measures were collected in the employee version of the questionnaire. We attempted controlling for several hospital- and 
ICU-level variables, collected in the manager version of the questionnaire, such as number of beds and number of full-time nurses. Since none of these variables was significant, they are omitted from the analyses presented below.

\section{RESULTS}

Summary statistics and correlations among the variables are presented in Table 1. The patterns of correlations generally follow the expected directions. To test the hypotheses in this study, we performed an ordinary least squares (OLS) regression analysis. Table 2 presents the results of this analysis. Model 1 regresses innovation on the study control variables, among which only intensive care nurse training is marginally related to innovation $(\beta=0.28, p<0.10)$. Model 2 tests Hypothesis 1 by including the three types of knowledge sharing into the set of independent variables. All three types of knowledge sharing, namely knowledge sharing through written contributions $(\beta=0.37, p<0.01)$, knowledge sharing through organizational communication $(\beta=0.41, p<0.01)$ and knowledge sharing through personal interaction $(\beta=0.20, p<0.05)$, were positively related to innovation. Thus, Hypothesis 1 is supported.

To rule out multicollinearity between the different types of knowledge sharing behaviors, we also estimated the variance inflation factors (VIF). There were no signs of multicollinearity, as all VIF were below the conservative cut-off value of 5 (mean VIF = 1.84; O’Brien, 2007). We tested Hypothesis 2 in Models 3 to 7. Based on Model 2, Model 3 also includes the main effect of control of care quality, which is not significant $(\beta=0.13, p>$ 0.10). The following three models respectively include the interaction terms between control of care quality and knowledge sharing through written contributions (Model $4 ; \beta=0.25, p>$ 0.10 ), organizational communication (Model $5 ; \beta=0.03, p>0.10$ ) and personal interaction (Model 6; $\beta=-0.41, p>0.10$ ). None of these interaction terms are significant. Finally, Model 
7 includes all three interaction terms, namely between control of care quality and knowledge sharing through written contributions $(\beta=0.53, p>0.10)$, organizational communication $(\beta=$ $-0.13, p>0.10)$ and personal interaction $(\beta=-0.59, p<0.05)$. Of the three interaction terms, only that of personal interaction is significant in the expected negative direction. Furthermore, the main effect of knowledge sharing through personal interaction is significant. These results, which provide partial support to Hypothesis 2, are plotted in Figure 1.

Insert Table 1 about here

Insert Table 2 about here

Insert Figure 1 about here

\section{Auxiliary Analyses}

Even though we found partial evidence in support of Hypothesis 2, the finding that control of care quality had a moderating effect only on the relationship between personal interaction and innovation was unexpected. Therefore, we decided to conduct auxiliary analyses that investigate how each facet of control of care quality (i.e., structural, process and outcome controls) moderates the relationship between knowledge sharing behaviors and innovation. These analyses are presented in Table 3. First, Model A1 in Table 3 presents the main effects of all control variables, the three aspects of knowledge sharing and the three types of control of care quality. Knowledge sharing through written contributions $(\beta=0.49, p$ $<0.01)$ and through organizational communication $(\beta=0.47, p<0.01)$ are positively 
associated with innovation. However, as Model A1 shows, unlike overall control of care quality which was not related to innovation in the main analysis (Model 3), process control is marginally negatively related to innovation $(\beta=-0.37, p<0.10)$, whereas outcome control is positively related to innovation $(\beta=0.56, p<0.05)$. The next three models further investigate the potential moderating effects of structural control (Model A2), process control (Model A3) and outcome control (Model A4) on the relationship between knowledge sharing and innovation. Of these auxiliary models, Model A3, which tests the moderating effect of process control, is the only model that results in significant interactive effects. In particular, the effect of process control on the relationship between personal interaction and innovation follows the same pattern reported in the main analyses (Model 7 in Table 2; see also Figure 1). However, process control also marginally moderates the effect of knowledge sharing through written contributions $(\beta=0.53, p<0.10)$, in an unexpected positive direction. These interesting findings deserve further discussion.

Insert Table 3 about here

\section{DISCUSSION}

It is increasingly acknowledged that nurses are not simply adopters of innovation, but also an important source of innovation in health care (McSheery \& Douglas, 2011). Innovation in ICU is often multidisciplinary (e.g., reduction of sedation during mechanical ventilation to shorten the length of ICU-stay). Nursing innovation revolves around human and environmental factors that enable reduction of sedation, such as better management of communication, pain, thirst, sleep, and mobilization. Therefore, it is becoming increasingly important to understand the factors that foster innovation in clinical practice. In this study, we 
show that knowledge sharing among ICU nurses is one such factor, as it is positively associated with individual nurse innovation. Furthermore, we show that this positive relationship holds true for all three types of knowledge sharing, namely, through written contributions (e.g., developing guidelines and protocols), through organizational communication (e.g., asking and answering relevant questions during meetings), and through personal interaction (e.g., helping less experienced colleagues at lunch or over email outside of working hours).

Our study further demonstrates that control of care quality, which has tightened in Denmark, Europe and much of the world (Lilford et al., 2004), may influence the positive relationship between knowledge sharing and innovation in nuanced ways. While we did not find control of care quality to weaken the positive relationship between all types of knowledge sharing and innovation, we found it to be the case with regard to knowledge sharing through personal interaction. In other words, when control of care quality is high within an ICU, as perceived by managers, informal conversations and voluntary helping behaviors between colleagues are less likely to foster innovation. The auxiliary analysis further shows that it is particularly the case when strong process control is in place, i.e., "control over what care providers do" (Pronovost et al., 2001). Strong process control in ICUs not only weakens but in fact inverts the positive relationship between knowledge sharing and innovation.

This finding is very much in line with our theorizing. The context of intensive care has changed in recent years with increased control (guidelines and procedures) and competition (research and innovation). Medical dominance in health care has decreased with better educated nurses and increased use of clinical guidelines (process control). While guideline construction might increase nursing innovation and influence, the use of guidelines threatens the autonomy and experience-based thinking of health care professionals. Increased 
health care costs and increased efficiency reduce the staffing ratio and might also reduce opportunities for informal knowledge sharing.

However, somewhat surprisingly, process control was also found to strengthen although only marginally - the effect of written contributions on innovation in ICUs. Even though this finding was unexpected, perhaps it makes sense in light of the following consideration. In preparing written documents such as research articles, clinical documents and protocols, nurses must necessarily seek foundation in established procedures of providing quality care. Otherwise, any innovation produced in these highly formalized and standardized documents would be deemed inadequate. Participation in producing and publishing written documents is likely to foster procedural innovations that can be "innovative" and valuable only if they observe and respect pre-established clinical guidelines for practice. Therefore, the stronger the demands for process control within ICUs, the more likely written contributions of ICU nurses can contribute to their innovation activities.

Finally, we did not find control of care quality to moderate the effect of organizational communication on innovation. Given that process control was the only type of control of care quality that exerted any influence, perhaps this finding can be explained as well. Organizational communication, which takes place predominantly in formalized settings such as department meetings, often revolves around administrative, managerial and organizational issues. These issues are somewhat outside the scope of clinical practice, which process measures aim to control. Thus, process control is unlikely to influence the innovation effects of organizational communications.

That said, it is also worth considering why process control (and not structural control or outcome control) was the only control measure that exerted an influence in the relationship between knowledge sharing and innovation. We argued that health care organizations need to balance between exploitation through operational excellence (efficiency) and exploration 
through innovation. A strong focus on efficiency, controlled through measures of care quality, may make knowledge sharing between nurses anchored in efficiency themes rather than discussion of more major innovations arising from practice. While we found to be the case for process control, this appears to not hold true of structural control, perhaps because ICU nurses may feel that how the provision of care is organized - or structured - is beyond the scope of their communication and innovation efforts. In other words, structure control may be taken for granted in the day-to-day practice of an ICU nurse. Alternatively, outcome control measures, which capture what happens to patients, are the end, rather than the means, of nursing practice, and can arguably be reached through either efficiency or innovation. Furthermore, the ultimate definition of effective healthcare may also be taken for granted. The aspect that ICU nurses actually have direct personal power and influence over is their everyday clinical practice, and process control measures aim to guide precisely everyday clinical practice.

\section{Implications for Theory}

There is an increasing pressure on ICU nurses and other clinicians to provide care of high quality (Flaatten, 2012; Pronovost et al., 2001), which may be achieved through better communication and increased knowledge sharing (Pronovost et al., 2004; Rangachari, 2008). Yet, as our findings suggest, controlling the quality of care may actually produce a paradox whereby useful, innovative informal communication between nurses is impaired. As others have argued, control of care quality may actually divert attention from genuine improvement and towards superficial improvement or even gaming behavior (i.e., manipulating the system); these dangers apply not just to outcome control but also process control (Lilford et al., 2004). Future research may further consider the trade-offs involved in stimulating exploitation (through control of care quality) versus exploration (through innovative knowledge sharing) in healthcare. We began delineating an important boundary condition, namely strong process 
control, under which knowledge sharing through personal interaction may lead to less nurse innovation. However, strong process control may be helpful in certain settings, such as when innovative written contributions are in place. A question that remains is, under which conditions are written contributions to be preferred over the arguably faster, more effective method of sharing knowledge face-to-face? This could be an interesting topic for future research.

\section{Implications for Practice}

Our findings suggest several implications for health care management practice. First, we may advise hospital administrators to loosen process control measures - but not necessarily structural and outcome control measures - if they are interested in stimulating the meaningful personal interaction between ICU nursing staff, it may positively stimulate nurse innovation. Indeed, tight control, over-managing and low quality relationships are some of the most significant barriers to successfully managing knowledge and innovation in health care organizations (for a review, see Nicolini et al., 2008). Alternative, managers may consider developing a climate where helping others, with an emphasis on younger colleagues, is desirable through, for instance, designing and implementing incentive systems to offset the negative effects of strong process control (von Krogh, 1998). Mentoring programs and/or programs that provide accessibility to the time and attention of experts and senior colleagues

may be put in place. Of course, incentive systems and similar type of programs run the risk of formalizing behaviors that are by definition informal, i.e., knowledge sharing through personal interaction. Alternatively, to improve the innovative effects of personal interaction, hospital administrators may undertake proactive efforts to endorse innovation. For example, they may attempt to coordinate knowledge exchange by setting up project debriefings and other forms of learning-oriented conversations (Rangachari, 2008). In fact, administrators are 
advised to consider a combination of several initiatives, since a multifaceted approach has been shown to be most effective (Cook et al., 2004).

\section{Limitations}

Our study needs to be viewed in light of some limitations. First, nonexperimental designs such as ours cannot assure that causality is fully established. To fully understand the processes through which knowledge sharing relates to innovation, we encourage future research to adopt longitudinal research designs with multiple time points, even though these designs bring with them another set of methodological problems (Menard, 1991; Ployhart \& Vandenberg, 2010; Singer \& Willett, 2003). A second potential shortcoming of our design is that common method variance cannot be ruled out completely since the dependent variable, i.e., innovation, and one of the predictor variables, i.e., knowledge sharing, were measured by self-reporting. Even though the widespread condemnation of this method is most likely exaggerated (Crampton \& Wagner, 1994; Lindell \& Whitney, 2001; Spector, 2006), to lessen the potential bias of common method variance, several procedures were implemented. On one hand, we assured anonymity and confidentiality of the respondents' responses, while the online survey platform did not allow respondents to return to a previous page, making retrospect editing of answers impossible. This design of the questionnaire contributed to diminish the effects of common method variance (Podsakoff et al., 2003). On the other hand, we were careful to design our study so that not all measures were collected from a single source. Instead, we made multi-source data collection efforts: one of the hypothesized predictor variables, i.e., control of care quality, was collected from nurse managers rather than employees. It has been argued that moderation effects, such as the one we have found, cannot be caused by common method variance (Chang et al., 2010). Hence, we are confident that common method variance is not a serious problem of this study. 
Finally, a potential limitation concerns the individual-level specification of our model. Even though nurses were nested within units, our theoretical focus was at the individual nurse level. In other words, we were first and foremost interested in the effects of individual nurse knowledge sharing behavior on individual nurse innovation potential, contingent on the unitlevel influence of control of care quality. Independent of our theorizing, however, we did attempted setting up multilevel analyses. This proved unfeasible since indices such as the ICC(1) that measure the amount of variance in individual-level responses that can be attributed to group-level properties were generally low (between 0.00 and 0.09 ). This low range did not suggest significant unit-level variance in either innovation or knowledge sharing (LeBreton \& Senter, 2008). Alternatively, controlling for unit-level fixed effects produced virtually identical results.

\section{Conclusion}

Despite its limitations, our study makes a strong contribution to nursing management and practice. In fact, we believe our study also contributes to health care and innovation management more broadly, given that the barriers and enablers of effective knowledge management in health care parallel those observed in other industries (Nicolini et al., 2008). We demonstrate that the increasing pressures to implement control of care quality and innovate may be conflicting, unless handled properly. Even though our study was conducted with a sample of ICUs, our findings that knowledge sharing is related to innovation, but only under certain conditions, is most likely to generalizable to a wide variety of settings. We hope this study may inspire future research to fully capture the complexity embedded in the relationship between knowledge sharing and innovation for clinical professionals with alternative and complementary research designs and methodologies. 


\section{REFERENCES}

Armstrong, S. J., \& Overton, T. S. 1977. Estimating non-response bias in mail surveys. Journal of Marketing Research, 14: 396-402.

Åmo, B. W. 2006. Employee innovation behaviour in health care: the influence from management and colleagues. International Nursing Review, 53(3): 231-237.

Berenholtz, S. M., Dorman, T., Ngo, K. \& Pronovost, P. J. 2002. Qualitative review of intensive care unit quality indicators. Journal of Critical Care, 17(1): 1-12.

Bock, G. W. \& Kim, Y.-G. 2002. Breaking the myths of rewards: An exploratory study of attitudes about knowledge sharing. Information Resources Management Journal 15(2):14-21.

Brechin A. 2000. Introducing critical practice. In A. Brechin, H. Browne \& M. Eby (Eds.), Critical Practice in Health and Social Care: pp. 25-47. London: Sage.

Chang, S., van Witteloostuijn, A., \& Eden, L. 2010. Common method variance in international business research. Journal of International Business Studies, 41: 178184.

Cook, D. J., Montori, V. M., McMullin, J. P., Finfer, S. R., \& Rocker, G. M. 2004. Improving patients' safety locally: changing clinician behaviour. The Lancet, 363(9416): 12241230.

Crampton, S.M., \& Wagner, J.A. 1994. Percept-percept inflation in micro organizational research: An investigation of prevalence and effect. Journal of Applied Psychology, 79: 67-76.

Cummings, J. N. 2004. Work groups, structural diversity, and knowledge sharing in a global organization. Management Science 50(3): 352-364.

Dalkir, K. 2005. Knowledge Management in Theory and Practice. Oxford: Elsevier. 
Donchin, Y., Gopher, D., Olin, M., Badihi, Y., Biesky, M., Sprung, C. L., et al. 1995. A look into the nature and causes of human errors in the intensive care unit. Critical Care Medicine, 23: 294-300.

Eisenhardt, K. M. 1985. Control: Organizational and economic approaches. Management Science, 31(2): 134-149.

Gurses, A. P. \& Carayon, P. 2007. Performance obstacles of intensive care nurses. Nursing Research 56(3): 185-194.

Hansen, M. 1999. The search-transfer problem: The role of weak ties in sharing knowledge across organization subunits. Administrative Science Quarterly 44: 82-111.

Hogel, M., Parboteeah, K.P. \& Munson, C.L. 2003. Team-level antecedents of individuals' knowledge networks. Decision Sciences, 34(4): 741-770.

Hu, L. T., \& Bentler, P. M. 1999. Cutoff criteria for fit indexes in covariance structure analysis: Conventional criteria versus new alternatives. Structural Equation Modeling: A Multidisciplinary Journal, 6: 1-55.

Hughes F. 2006. Nurses at the forefront of innovation. International Nursing Review, 53(2): 94-101.

ICN. 2009. Delivering Quality, Serving Communities: Nurses Leading Care Innovation. International Council of Nurses, Geneva, Switzerland.

Jeppesen, L. B., \& Frederiksen, L. 2006. Why do users contribute to firm-hosted user communities? The case of computer-controlled music instruments. Organization Science, 17(1): 45-63.

LeBreton, J. M., \& Senter, J. L. 2008. Answers to 20 questions about interrater reliability and interrater agreement. Organizational Research Methods, 11(4): 815-852. 
Lilford, R., Mohammed, M. A., Spiegelhalter, D., \& Thomson, R. 2004. Use and misuse of process and outcome data in managing performance of acute medical care: avoiding institutional stigma. The Lancet, 363(9415): 1147-1154.

Lin, H.-F. 2007. Knowledge sharing and firm innovation capability: an empirical study. International Journal of Manpower, 28 (3/4): 315 - 332.

Lindell, M.K., \& Whitney, D.J. 2001. Accounting for common method variance in crosssectional research designs. Journal of Applied Psychology, 86: 114-121.

Locke, R., Leach, C., Kitsell, F. \& Griffith, J. 2011. The impact on the workload of the ward manager with the introduction of administrative assistants. Journal of Nursing Management 19 (2): 177-185.

March, J.G. 1991. Exploration and exploitation in organizational learning. Organization Science 2(1): 71-87.

Manion J. 1993. Change from within, nurse entrepreneurs as health care innovators. American Nurses Association, Kansas City.

McSheery, R. \& Douglas, M. 2011. Innovation in nursing practice: a means to tackling the global challenges facing nurses, midwives and nurse leaders and managers in the future. Journal of Nursing Management 19: 165-169.

Menard, S. 1991. Longitudinal Research. Newbury Park: Sage Publications.

Nelson J. E., Mulkerin, C. M., Adams, L. L. \& Pronvost, P. J. 2007 Improving comfort and communication in the ICU: A practical new tool for palliative care performance measurement and feedback. Quality \& Safety in Health Care 15: 264-271.

Nicolini, D., Powell, J., Conville, P., \& Martinez-Solano, L. 2008. Managing knowledge in the healthcare sector: A review. International Journal of Management Reviews, 10(3): 245-263. 
Nonaka, I., Von Krogh, G. \& Voelpel, S. 2006. Organizational knowledge creation theory: evolutionary paths and future advances. Organization Studies, 27(8): 1179-1208.

O’Brien, R. M. 2007. A caution regarding rules of thumb for variance inflation factors. Quality \& Quantity, 41(5): 673-690.

Ott, J. \& Ross, C. 2014. The journey toward shared governance: the lived experience of nurse managers and staff nurses. Journal of Nursing Management, 22(6): 761-768.

Ployhart, R. E., \& Vandenberg, R. J. 2010. Longitudinal research: The theory, design, and analysis of change. Journal of Management, 36: 94-120.

Podsakoff, P.M., MacKenzie, S.B., Lee, J.-Y., \& Podsakoff, N.P. 2003. Common method biases in behavioral research: A critical review of the literature and recommended remedies. Journal of Applied Psychology, 88: 879-903.

Pronovost, P. J., Miller, M. R., Dorman, T., Berenholtz, S. M. \& Rubin, H. 2001. Developing and implementing measures of quality of care in the intensive care unit. Current Opinion in Critical Care, 7(4): 297-303.

Pronovost, P. J., Nolan, T., Zeger, S., Miller, M., \& Rubin, H. 2004. How can clinicians measure safety and quality in acute care? The Lancet, 363(9414): 1061-1067.

Rademakers, J., Delnoij, D. \& de Boer, D. 2011. Structure, process or outcome: which contributes most to patients' overall assessment of healthcare quality? BMJ Quality \& Safety, 20: 326-331.

Rangachari, P. 2008. Knowledge sharing networks related to hospital quality measurement and reporting. Health Care Management Review, 33(3): 253-263.

Reid, F. 2003. Creating a knowledge sharing culture among diverse business units. Employment Relations Today, 30(3): 43-49. 
Richer, M. C., Ritchie, J. \& Marchionni, C. 2009 'If we can't do more, let's do it differently!': Using appreciative inquiry to promote innovative ideas for better health care work environments. Journal of Nursing Management 17(8): 947-955.

Sáenz, J., Aramburu, N. \& Rivera, O. 2009. Knowledge sharing and innovation performance: A comparison between high-tech and low-tech companies. Journal of Intellectual Capital 10(1): 22-36.

Singer, J. D., \& Willett, J. B. 2003. Applied longitudinal data analysis: Modeling change and event occurrence. Oxford: Oxford University Press.

Snell, S. A. 1992. Control theory in strategic human resource management: The mediating effect of administrative information. Academy of Management Journal 35(2): 292 327.

Spear, S. J. 2005. Fixing health care from the inside, today. Harvard Business Review, 83: 78-91.

Spector, P.E. 2006. Method variance in organizational research: Truth or urban legend? Organizational Research Methods, 9: 221-232.

Stevens K.R. 2001. Systematic reviews: The heart of evidence based practice. AACN Clin Issues 12(4): 529-538.

Subramaniam, M. \& Youndt, M.A. 2005. The influence of intellectual capital on the types of innovative capabilities. Academy of Management Journal 48(3): 450-463.

Syme, R. \& Stiles, C. 2012. Promoting nursing research and innovation by staff nurses. Applied Nursing Research 25(1): 17-24.

Tross, G. \& Cavanagh, S. J. 1996. Innovation in nursing management: Professional, management and methodological considerations. Journal of Nursing Management, 4(3): 143-149. 
Wang, Z. \& Wang, N. 2012. Knowledge sharing, innovation and firm performance. Expert Systems with Applications 39(10): 8899-8908.

Welbourne, T. M., Johnson, D. E., \& Erez, A. 1998. The role-based performance scale: Validity analysis of a theory-based measure. Academy of Management Journal, 41(5): 540-555.

Weng, R. H., Huang, C. Y., Chen, L. M. \& Chang, L. Y. 2015. Exploring the impact of transformational leadership on nurse innovation behavior: A cross-sectional study. Journal of Nursing Management, 23(4): 427-439.

Yi, J. 2009. A measure of knowledge sharing behavior: scale development and validation. Knowledge Management Research \& Practice, 7: 65-81. 
TABLE 1

Summary Statistics and Correlations between Study Variables ${ }^{a}$

\begin{tabular}{|c|c|c|c|c|c|c|c|c|c|c|c|c|}
\hline & & $M$ & $S D$ & 1 & 2 & 3 & 4 & 5 & 6 & 7 & 8 & 9 \\
\hline 1 & Innovation & 3.21 & 0.74 & & & & & & & & & \\
\hline 2 & Knowledge sharing through written contributions & 1.80 & 0.65 & $0.53^{*}$ & & & & & & & & \\
\hline 3 & $\begin{array}{l}\text { Knowledge sharing through organizational } \\
\text { communication }\end{array}$ & 2.89 & 0.65 & $0.51^{*}$ & $0.60^{*}$ & & & & & & & \\
\hline 4 & Knowledge sharing through personal interaction & 2.50 & 0.51 & $0.32^{*}$ & $0.30^{*}$ & $0.31^{*}$ & & & & & & \\
\hline 5 & Control of care quality & 4.43 & 0.33 & 0.04 & 0.02 & 0.07 & 0.08 & & & & & \\
\hline 6 & Intensive care nursing training $(0=$ no, $1=$ yes $)$ & 0.80 & 0.40 & 0.08 & $0.32^{*}$ & $0.25^{*}$ & 0.02 & 0.02 & & & & \\
\hline 7 & Age & 44.13 & 9.77 & -0.07 & 0.11 & 0.14 & -0.10 & -0.05 & $0.36^{*}$ & & & \\
\hline 8 & $\operatorname{Sex}(0=$ male, $1=$ female $)$ & 0.95 & 0.23 & 0.00 & 0.00 & 0.14 & 0.14 & $0.18^{*}$ & -0.02 & 0.01 & & \\
\hline 9 & Nursing experience & 16.79 & 9.84 & -0.06 & $0.20^{*}$ & $0.26^{*}$ & 0.00 & -0.04 & $0.43^{*}$ & $0.83^{*}$ & 0.03 & \\
\hline 10 & Number of working hours per week & 34.47 & 3.76 & 0.07 & $0.15^{*}$ & $0.15^{*}$ & 0.11 & -0.04 & 0.03 & -0.06 & -0.12 & -0.07 \\
\hline
\end{tabular}

${ }^{a} n=180$

$p<0.05$ 
TABLE 2

Results of Main OLS Regression Analysis ${ }^{a}$

\begin{tabular}{|c|c|c|c|c|c|c|c|}
\hline & $\begin{array}{l}\text { Model } \\
1\end{array}$ & $\begin{array}{l}\text { Model } \\
2\end{array}$ & $\begin{array}{l}\text { Model } \\
3\end{array}$ & $\begin{array}{l}\text { Model } \\
4\end{array}$ & $\begin{array}{l}\text { Model } \\
5\end{array}$ & $\begin{array}{l}\text { Model } \\
6\end{array}$ & $\begin{array}{l}\text { Model } \\
7\end{array}$ \\
\hline $\begin{array}{l}\text { Knowledge sharing through written contributions } \\
\text { (KSWC) }\end{array}$ & & $0.37^{* *}$ & $0.45^{* *}$ & -0.66 & $0.46^{* *}$ & $0.45^{* *}$ & -1.94 \\
\hline $\begin{array}{l}\text { Knowledge sharing through organizational } \\
\text { communication (KSOC) }\end{array}$ & & $0.41^{* *}$ & $0.49^{* *}$ & $0.50^{* *}$ & 0.37 & $0.50^{* *}$ & 1.12 \\
\hline Knowledge sharing through personal interaction (KSPI) & & $0.20^{*}$ & 0.13 & 0.14 & 0.13 & 1.94 & $2.73^{*}$ \\
\hline Control of care quality & & & 0.13 & -0.30 & 0.06 & 1.17 & 1.07 \\
\hline Control of care quality x KSWC & & & & 0.25 & & & 0.53 \\
\hline Control of care quality x KSOC & & & & & 0.03 & & -0.13 \\
\hline Control of care quality x KSPI & & & & & & -0.41 & $-0.59^{*}$ \\
\hline Intensive care nursing training $(0=$ no, $1=$ yes $)$ & $0.28^{\dagger}$ & 0.03 & -0.11 & -0.11 & -0.11 & -0.12 & -0.12 \\
\hline Age & -0.01 & 0.00 & 0.00 & 0.00 & 0.00 & 0.00 & 0.00 \\
\hline Sex $(0=$ male, $1=$ female $)$ & 0.04 & -0.26 & $-0.51^{*}$ & $-0.54^{*}$ & $-0.51^{*}$ & $-0.51^{*}$ & $-0.57^{* *}$ \\
\hline Nursing experience & 0.00 & $-0.02^{*}$ & $-0.02^{*}$ & $-0.02^{*}$ & $-0.02^{*}$ & $-0.02^{*}$ & $-0.02^{*}$ \\
\hline Number of working hours per week & 0.01 & -0.02 & $-0.02^{*}$ & $-0.03^{*}$ & $-0.03^{*}$ & $-0.02^{*}$ & $-0.03^{*}$ \\
\hline Intercept & $3.08^{* *}$ & $1.78^{* *}$ & $1.64^{\dagger}$ & $3.60^{\dagger}$ & 1.99 & -2.89 & -2.38 \\
\hline$R$-squared & 0.03 & 0.41 & 0.50 & 0.51 & 0.50 & 0.51 & 0.52 \\
\hline
\end{tabular}

$$
\begin{aligned}
& { }^{a} n=180 \\
& { }^{* *} p<0.01 \quad * \\
&
\end{aligned}
$$


TABLE 3

Results of Auxiliary OLS Regression Analysis ${ }^{a}$

\begin{tabular}{|c|c|c|c|c|}
\hline & $\begin{array}{l}\text { Model A1 } \\
\text { Main } \\
\text { effects only }\end{array}$ & $\begin{array}{l}\text { Model A2 } \\
\text { CCQ }=\text { Structural } \\
\text { control }\end{array}$ & $\begin{array}{l}\text { Model A3 } \\
\text { CCQ }=\text { Process } \\
\text { control }\end{array}$ & $\begin{array}{l}\text { Model A4 } \\
\text { CCQ }=\text { Outcome } \\
\text { control }\end{array}$ \\
\hline $\begin{array}{l}\text { Knowledge sharing through written contributions } \\
\text { (KSWC) }\end{array}$ & $0.49^{* *}$ & -0.76 & -1.92 & -0.72 \\
\hline $\begin{array}{l}\text { Knowledge sharing through organizational } \\
\text { communication (KSOC) }\end{array}$ & $0.47^{* *}$ & $1.85^{\dagger}$ & 0.47 & -0.11 \\
\hline Knowledge sharing through personal interaction (KSPI) & 0.14 & 0.91 & $3.80^{* *}$ & 1.61 \\
\hline Structural control & 0.05 & 0.94 & 0.05 & 0.06 \\
\hline Process control & $-0.37^{\dagger}$ & $-0.38^{\dagger}$ & 0.70 & -0.33 \\
\hline Outcome control & $0.56^{*}$ & $0.56^{*}$ & $0.57^{*}$ & 0.46 \\
\hline$\underline{C C Q} \times \mathrm{KSWC}$ & & 0.28 & $0.53^{\dagger}$ & 0.26 \\
\hline$\underline{C C Q} \times \mathrm{KSOC}$ & & -0.31 & 0.01 & 0.14 \\
\hline$\overline{C C Q} \times \mathrm{KSPI}$ & & -0.18 & $-0.82^{* *}$ & -0.33 \\
\hline Intensive care nursing training $(0=$ no, $1=$ yes $)$ & -0.14 & -0.14 & -0.18 & -0.14 \\
\hline Age & 0.00 & 0.00 & 0.00 & 0.00 \\
\hline $\operatorname{Sex}(0=$ male, $1=$ female $)$ & $-0.52^{*}$ & $-0.55^{*}$ & $-0.57^{* *}$ & $-0.54^{*}$ \\
\hline Nursing experience & $-0.02^{*}$ & $-0.02^{*}$ & $-0.02^{* *}$ & $-0.02^{*}$ \\
\hline Number of working hours per week & $-0.02^{*}$ & $-0.03^{*}$ & $-0.02^{*}$ & $-0.02^{*}$ \\
\hline Intercept & 1.17 & -2.57 & -3.69 & 1.41 \\
\hline$R$-squared & 0.52 & 0.54 & 0.56 & 0.53 \\
\hline
\end{tabular}

${ }_{* *}^{a}$ The abbreviation CCQ stands for "control of care quality". $n=180$

${ }^{* *} p<0.01 \quad{ }^{*} p<0.05 \quad{ }^{\dagger} p<0.10$ 
FIGURE 1

The Interactive Effect of Knowledge Sharing through Personal Interaction and Control of Care Quality

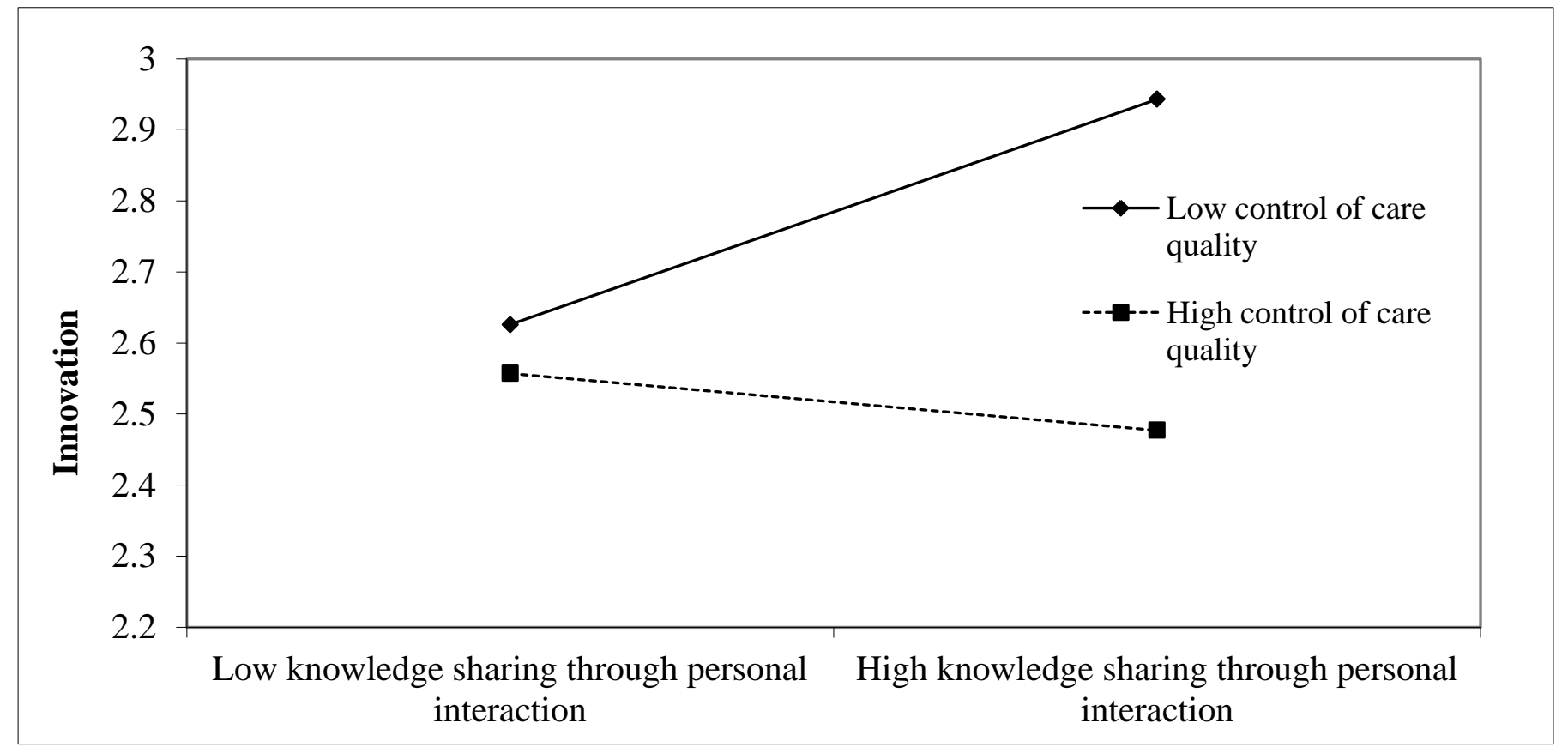

Note: The plot is based on results reported in Table 2, Model 7. 


\section{APPENDIX \\ Scales Used}

\section{Innovation}

1. Coming up with new ideas

2. Working to implement new ideas

3. Finding improved ways to do things

4. Creating better processes and routines

\section{Knowledge Sharing}

\section{Written contributions}

1. Participate in writing a research and development article (e.g., for a nursing journal)

2. Participate in writing local clinical guidelines

3. Participate in writing national clinical guidelines (i.e., sent to Clearing House for Clinical Guidelines)

4. Inform colleagues in writing about the projects you participate in

5. Contribute to the development of protocols to improve care in your department

6. Discuss staffing issues through group emails or online discussion forums

\section{Organizational communication}

7. Participate in a journal club

8. Participate in problem-solving during department meetings

9. Answer others' questions during department meetings

10. Ask question during department meetings

11. Tell success stories of nursing experiences that could benefit your department

12. Tell colleagues about adverse events during department meetings

\section{Personal interaction}

13. Support a less experienced colleague outside of your normal working hours

14. Spend time on personal conversations with other critical care nurses to help them with work-related problems (e.g., conversations over lunch, over the phone)

15. Discuss organizational issues in informal contexts

16. Use your own experience in informal contexts to help colleagues avoid accidents

17. Chat online (e.g., in Facebook groups) to help colleagues with their work-related problems

18. Spend time on personal e-mail correspondence with other intensive care nurses to help them with their work-related problems

\section{Control of Care Quality}

\section{Structure}

1. Presence of ICU medical director

2. Daily rounds by an intensive care physician

3. ICU nurse-to-patient ratio

\section{Process}

4. Use of barrier precautions while inserting central venous catheters

5. Daily interruption of sedation

6. Rate of self-extubation

7. Appropriate use of stress ulcer prophylaxis

8. Appropriate use of deep venous thrombosis prophylaxis

\section{Outcome}

9. Minimization of sepsis

10. Minimization of length of ICU stay

11. Minimization of ventilator-associated pneumonia

12. Minimization of the duration of mechanical ventilation

13. Minimization of the consumption of medicines

14. Optimization of pain management

15. Optimization of family and patient satisfaction with care

16. Optimization of end-of-life care 